\title{
Website Customization: Exploring a Tag-Based Approach in the Australian Banking Context
}

\author{
Rajinesh Ravendran \\ Queensland University of Technology (QUT), \\ 2 George Street, Brisbane, QLD 4000 \\ \{r. ravendran\} @qut. edu . au
}

\begin{abstract}
Description: Website customization is important to better fulfill the needs and wants of individual customers. Tags assigned to web resources are suitable to facilitate website customization.
\end{abstract}

Area: Website customization, online banking, tags.

\section{Problem}

This research addresses the problem of website customization in online banking, particularly in the Australian context. Australia has the fourth highest online banking adoption rate among developed nations (behind Canada, US and UK) ${ }^{1}$ and Australian consumers prefer online banking over ATM, phone and branch ${ }^{2}$. The existence of large number of users who use online banking services on a regular basis presents a wide opportunity for customization. A recent study by Rahim and JieYing [11] on online banking customer satisfaction in the Australian context highlighted website customization as an imperative dimension, particularly among the younger generation, however, this dimension is poorly addressed.

This research is significant because website customization can enable online banking to be more responsive to the individual needs of each user [11]. Customization helps to bind customers into a long-term relationship despite a shortterm discomfort [2]. Such relationships are vital as they directly translate into ongoing profits [8]. In the banking context, customers are more likely to purchase a new product or service from their existing bank compared to a new bank [5]. For this reason, it is significant that online banking providers incorporate website customization as part of the offerings.

Prior research on website customization indicates that customization approaches can be grouped into two categories: static and dynamic [2]. Static approaches are typically user-based, where the user is responsible for initiating and carrying out the customization (e.g., content and feature selection during registration). Static approaches are simple, straight-forward and put users in control. However, they overlook the impacts of dynamic approaches such as the ability to predict what a user

\footnotetext{
${ }^{1}$ http: / / www.comscore.com/Press_Events/Press_Releases/2008/07/Can ada_Online_Banking

${ }^{2}$ http://au.nielsen.com/news/20070426.shtml
} 
might find interesting or useful [2]. Also, users do not like to spend time configuring complex customization features [6]. Dynamic approaches, on the other hand, are system-based, with the system entirely responsible for initiating and carrying out customization (e.g., web usage analysis and collaborative filtering). They require minimal effort from users but are complex and sophisticated. Some of the known issues with dynamic approaches include expensive computational cost, technical issues and ethical concerns [9]. Additionally, dynamic approaches are likely to fail in dynamic settings [6].

This research proposes tags as a suitable technology to facilitate website customization. Tags, part of Web 2.0, represent Web resources (e.g., photo, video, people, etc) in ways familiar to individual users, primarily for personal information management (PIM). Tags are largely personal and contextual [6], and considered as a potential source of knowledge [1]. Recognized as an easy-to-use, dynamic and engaging technology, tags aid users to recall and retrieve information content [7] and when represented as tag clouds they facilitate visual information retrieval [3]. Also, the underlying meanings of tags may be discovered through semantic analysis to form associations between like-minded individuals [10]. These characteristics of tags make them suitable for customization and offer a valuable alternative approach.

In the financial space, tags assist personal financial management via tools such as Mint (http://www.mint.com) and Yodlee (http://www.yodlee.com), where a user can assign tags to transactional data for budgeting, expense tracking, etc. These tools, however, only allow tags to be assigned to financial transactions at a high level as category or description, but not at a lower level for details such as bank account or biller. This research explores the use of tags at a granular level in a broader context of personal financial management to facilitate customization in online banking. The types of customization proposed by Fung [2] (remembering, comprehension and associative) is used as a basis.

\section{Claim}

Tags are suitable to facilitate website customization alongside personal financial management. The proposed tag-based approach is user- and system-based with users as active participants of the customization process and the system providing customization based on user input (tags). The inclusion of both user and system in the customization process is advantageous for a complete customization. Such an approach will allow users to drive customization and simultaneously enable dynamic, system-based customization features.

Tags and tag clouds can offer a more intuitive and interactive website design. Since tags represent resources in a personal manner, tags can be used to personalize website interaction and comprehend user intentions via simple tag selections. Possible actions may be inferred on two tags based on their tag-resource association, which can enhance website interaction and experience. Also, based on semantic relations of tags across the community, relevant information can be aggregated and provided to users. 


\section{Methods}

A mixed-method approach is proposed for this research, which includes a case study and software-based prototyping.

A case study has been conducted to identify the range of taggable resources found on online banking websites (mobile banking inclusive). The case study focused on two leading banks in Australia: Commonwealth Bank and Suncorp Bank. The personal banking websites of both banks were examined for potential taggable resources. Five resources were identified: account, reference, biller, application and message.

Software-based prototyping using an iterative approach is proposed to evaluate the suitability of tag-based website customization. This will allow users to provide feedback based on their 'real' experience that can be integrated into the prototype in the next iteration. A total of three iterations will be executed with each iteration comprising of three phases: design, development and evaluation. The prototype to be developed will be scenario-based where two key banking tasks, namely fund transfer and bill payment will be customized through tag integration. The prototype will be evaluated via an experimental design using pretest-posttest control group design [2]. A posttest questionnaire will be used to gather experiential feedback from participants on the utility and usability of the customization provided, as perceived by them.

The experiment results will be analyzed using ANOVA and interpreted by drawing on relevant literature in the space of HCI and ecommerce / banking customization. The results will be presented to the user-interaction and ecommerce research community.

\section{Solution}

The goal of the proposed tag-based approach is to simplify online banking activities, provide an intuitive interaction and offer personalized information to banking users. Online banking users will be able to quickly access and manage previous banking tasks (e.g., fund transfer, bill payment, etc) or resources (e.g., account, messages, etc) represented as tags; carry out banking activities by simply selecting appropriate tags (e.g., "Savings" + "Dad" to transfer money from savings account to dad's account); and discover related services and their popularity (usage) through associations with like-minded individuals based on tag similarity (e.g., "Vodafone" is semantically related to "Telstra" and "Optus", which are Australian telecom companies).

The outcome of this research will be a set of guidelines for designing and implementing tag-based customization. The guidelines will be akin to interaction design patterns in that offering solutions to different customization types and explaining when, how and why to use it (by quoting examples off the prototype).

\section{Contribution}

The contribution of this research will be the design and implementation of tags, expressed as interaction patterns, to facilitate website customization in online banking. This is expected to benefit financial institutions and system designers. 
Acknowledgement. This research is sponsored by the Smart Services Cooperative Research Centre (CRC) of Australia (http://www.smartservicescrc.com.au).

\section{References}

1. Durao, F., Dolog, P.: A personalized tag-based recommendation in social web systems. Paper presented at the International Workshop on Adaptation and Personalization for Web 2.0 (2009)

2. Fung, T.: Banking with a personalized touch: Examining the impact of website customization on commitment. Electronic Commerce Research 9(4), 296-309 (2008)

3. Hassan-Montero, Y., Herrero-Solana, V.: Improving tag-clouds as visual information retrieval interfaces. Paper presented at the International Conference on Multidisciplinary Information Sciences and Technologies, InSciT 2006, Mérida, Spain (2006)

4. Hiltunen, M., Heng, L., Helgesen, L.: Personalized Electronic Banking Services. In: Karat, C.-M., Blom, J.O., Karat, J. (eds.) Designing Personalized User Experiences in eCommerce, pp. 119-140. Springer, Heidelberg (2004)

5. Marlow, C., Naaman, M., Boyd, D., Davis, M.: HT06, tagging paper, taxonomy, Flickr, academic article, to read. Paper presented at the 17th Conference on Hypertext and Hypermedia, Odense, Denmark (2006)

6. Nielsen, J.: Personalization is Over-Rated (1998), http: / /www.useit.com/alertbox/981004.html

7. Panke, S., Gaiser, B.: With my head up in the clouds: using social tagging to organize knowledge. Journal of Business and Technical Communication 23(3), 318-349 (2009)

8. Peppers, D., Rogers, M.: The one to one future: Building relationships on customer at a time. Currency Doubleday, New York (1996)

9. Pierrakos, D., Paliouras, G., Papatheodorou, C., Spyropoulos, C.: Web usage mining as a tool for personalization: A survey. User Modeling and User-Adapted Interaction 13(4), 311-372 (2003)

10. Qi Xin, M., Uddin, M.N., Geun-Sik, J.: The wordNet based semantic relationship between tags in folksonomies. Paper presented at the 2nd International Conference on Computer and Automation Engineering (ICCAE), Singapore (2010)

11. Rahim, M.M., JieYing, L.: An empirical assessment of customer satisfaction with Internet Banking applications: An Australian experience. Paper presented at the 12th International Conference on Computers and Information Technology, ICCIT (2009) 